\title{
Efeitos da música clássica como elemento de enriquecimento ambiental em Mus musculus em cativeiro (Rodentia: Muridae)
}

\author{
José Geraldo Pereira da Cruz* \\ Débora Delwing Dal Magro \\ Júlia Niehues da Cruz \\ Universidade Regional de Blumenau \\ Centro de Ciências Exatas e Naturais - Departamento de Ciências Naturais \\ Rua Antônio da Veiga, 140 \\ CEP 89010-971 - Blumenau - Santa Catarina \\ *Autor para Correspondência \\ jgcruz@furb.br
}

Submetido em 28/09/2009

Aceito para publicação em 15/03/2010

\section{Resumo}

No ambiente selvagem, os animais são submetidos a mudanças constantes nos estímulos sensoriais. Entretanto, o ambiente de cativeiro é muito mais pobre em termos de estímulos fornecidos aos animais alojados no seu interior. Numa tentativa de remediar esta situação e promover um melhor bem estar, camundongos (Mus musculus) foram expostos a duas condições: sem estímulos auditivos e com música clássica. Em todos os experimentos foi utilizada uma bateria de testes comportamentais. Os resultados demonstram uma diminuição significativa na imobilidade no nado forçado, aumento de entradas nos braços fechados do labirinto em cruz elevado e diminuição na imobilidade no campo aberto, nos animais que haviam sido pré-expostos anteriormente a $24 \mathrm{~h}$ de música e sugerem que a música clássica causas mudanças na atividade motora em camundongos. Este estudo leva a conclusão que o enriquecimento do ambiente causa profundos efeitos sobre o comportamento de camundongos nos testes comportamentais e a música clássica é um método relativamente simples de contribuir para o bem estar de camundongos em cativeiro, mas pode comprometer resultados de experimentos como o nado forçado.

Unitermos: campo aberto, camundongos, enriquecimento ambiental, labirinto em cruz elevado, nado forçado

\section{Abstract}

Effects of classical music as part of environmental enrichment in captive Mus musculus (Rodentia: Muridae). In the wild, animals are exposed to an ever-changing array of sensory stimuli. The captive environment, by contrast, is generally much more impoverished in terms of the cues it offers the animals housed within. In a bid to remedy this, and promote better welfare, mice (Mus musculus) were exposed to two conditions: no auditory stimulation, and stimulation with classical music. In all experiments, a battery of behavior tests was used. The results demonstrated significantly decreased immobility in the forced swim, increased enclosed arm entries in the plus-maze, and decreased immobility in the open-field, in animals that had been pre-exposed to music $24 \mathrm{~h}$ earlier, suggesting that changes in mouse motor activity were caused by classical music. This study led to the conclusion that environmental enrichment may have profound effects on the behavior of mice in 
behavioral tests, and that classical music can be a relatively simple method of contributing to the well-being of captive mice, but it can affect the results of experiments such as forced swimming.

Key words: environment enrichment, forced swim, mice, open field, plus maze

\section{Introdução}

No ambiente natural, os animais são expostos a mudanças constantes nos estímulos sensoriais. Entretanto, quando mantidos em cativeiro, recebem poucos estímulos. Várias pesquisas foram planejadas no sentido de melhorar as condições físicas e/ou relações sociais destes animais. O enriquecimento do ambiente é iniciativa mais comum, podendo ser considerada como qualquer técnica destinada a melhorar o funcionamento biológico do animal em cativeiro, através de modificações do ambiente (Newberry, 1995). Os objetivos do enriquecimento ambiental não são específicos e estão relativamente abertos ao debate, mas geralmente são aceitas estratégias de enriquecimento que incentivem os padrões comportamentais típicos da espécie, aumente a capacidade de lidar com desafios, melhore o repertório comportamental, aumente de forma positiva a utilização do ambiente e/ou reduza ou elimine padrões de comportamentos aberrantes, por exemplo, estereotipias (Wells, 2009).

Nos últimos anos, alguma atenção tem sido dirigida, no sentido de explorar o impacto da estimulação sensorial como um método de enriquecimento ambiental para animais em cativeiro. Entretanto, as investigações sobre o mérito de tais estímulos tem sido esporádicos e as conclusões de sua utilização obscuras.

O valor da música para o bem estar psicológico dos seres humanos está relativamente bem documentado. Estudos sugerem que nosso humor (McCraty et al., 1998) e comportamento (Yalch e Spangenber, 2000), podem ser influenciados por estímulos auditivos; indicando que a música poderia ser utilizada no enriquecimento do ambiente para animais em cativeiro.

Estudos sobre os efeitos da música em animais em cativeiro apresentam resultados conflitantes e, levantam questões a serem respondidas, sobre o fato da música em cativeiro simplesmente acrescentar um ruído, um estresse ou um benefício aos animais mantidos neste ambiente. Muitos estudos em roedores indicam que a música aumenta o estresse fisiológico (McCarthy et al., 1992; Morton et al., 2001). Entretanto, outras pesquisas mostram que a música leva á comportamento positivos (Wells et al., 2008) e benefícios fisiológicos em roedores (Núñez et al., 2002; Sutoo e Akiyama, 2004; Nakamura et al., 2007). Sendo sugerido que ruído constante de fundo, durante o dia, apresenta algumas vantagens na criação destes animais, diminuindo a excitabilidade e reduzindo os sustos causados por ruídos repentinos (National Research Council, 1996; Sherwin, 2002). Outros trabalhos realizados com música de diferentes autores clássicos (Mozart, Strauss, Bach e Grieg), demonstraram um efeito enriquecedor destes estímulos auditivos sobre uma grande variedade de espécies (Wells et al., 2002; 2006; 2008; Videan et al., 2007; Wells, 2009). Estes trabalhos em conjunto, permitem estabelecer que músicas de gênero ou estilos diferentes, devem ser consideradas no enriquecimento do ambiente.

Dentro deste contexto comportamental, procuramos determinar em Mus musculus, a capacidade da música clássica de Mozart de modificar o comportamento destes animais, através de avaliações realizadas em três testes: o nado forçado, um modelo normalmente utilizado para estudos de drogas com efeitos antidepressivos; o labirinto em cruz elevado, um modelo animal de ansiedade e, o campo aberto, que permite determinar atividade motora geral; com a finalidade de elucidar o valor da estimulação sonora como um método de enriquecimento em cativeiro para camundongos criados em cativeiro.

\section{Material e Métodos}

\section{Animais}

Foram utilizados camundongos da linhagem Swiss (Mus musculus), machos, 2 meses de idade, com peso médio $28 \mathrm{~g}$, procedentes do Biotério Central da Universidade Regional de Blumenau. Os animais foram mantidos em gaiolas coletivas, com 8 animais, 
a $21 \pm 1^{\circ} \mathrm{C}$, e alimentados com ração padrão e água ad libitum. Este estudo foi aprovado pelo Comitê de Ética na Experimentação Animal de acordo com orientações institucionais.

\section{Exposição à música}

Camundongos foram mantidos durante $24 \mathrm{~h}$ sobre estímulos auditivos da música de Mozart (Sonata número 10, em $\mathrm{B}$ maior, KV361, Largo), tocada repetidamente em um leitor de CD. Animais controle, foram mantidos nas mesmas condições do ambiente, onde não havia nenhum som, exceto o produzido pelo ar condicionado. O nível do som do grupo controle foi de $55 \mathrm{~dB}$ e o da música de $65-75 \mathrm{~dB}$ na caixa moradia. Após este período os animais foram submetidos aos testes comportamentais: nado forçado, labirinto em cruz elevado e campo aberto.

\section{Nado forçado}

O nado forçado foi imposto individualmente por $5 \mathrm{~min}$, colocando-se o animal em um compartimento de vidro com $50 \mathrm{~cm}$ de altura e $30 \mathrm{~cm}$ de diâmetro, contendo água a $26^{\circ} \mathrm{C}$, em quantidade suficiente para se ter $12 \mathrm{~cm}$ de profundidade. A imobilidade observada na situação do nado forçado é considerada uma manifestação equivalente ao da depressão psiquiátrica (Porsolt et al., 1977; Michelan et al., 2006). Definiuse como imobilidade do nado forçado o período que o animal cessa seus movimentos, permanecendo em postura semiverticalizada, com apoio na ponta de uma das patas posteriores no fundo, ou em flutuação, mantendo apoio de uma ou ambas as patas superiores na parede do compartimento e a cabeça verticalizada acima da superfície da água. Os movimentos rápidos de correção postural após a perda lenta e progressiva de equilíbrio, observadas depois de instalado o episódio de imobilidade, não foram considerados como finalização. Estas foram estipuladas como sendo a procura de novas posturas, locomoções e atividade exploratória com movimentos sequenciados da cabeça. A água foi renovada e a temperatura corrigida com adição de água fria ou quente antes do teste de cada animal. A soma cumulativa das durações dos episódios de imobilidade durante o período de $5 \mathrm{~min}$ de natação forçada foi obtida em cronômetro manual e, o número de finalizações anotadas pelo observador.

\section{Labirinto em cruz elevado}

O labirinto em cruz elevado é formado de dois braços abertos (21,5 x 7,5cm cada um) e outros dois braços opostos do mesmo tamanho, fechados com paredes laterais de $31 \mathrm{~cm}$ de altura. Os braços abertos e fechados, elevados $38 \mathrm{~cm}$ do solo, cruzavam-se perpendicularmente formando uma cruz, delimitada por uma área central de $7,5 \times 7,5 \mathrm{~cm}$. O labirinto foi colocado em cubículo com isolamento acústico, iluminado por uma lâmpada vermelha (60W) e situada $150 \mathrm{~cm}$ acima do aparato. Cada animal foi exposto durante cinco minutos ao labirinto em cruz elevado (Pellow et al., 1985). Neste período, foram observados o número de entradas e o tempo gasto em ambos os braços, bem como o tempo gasto na área central.

\section{Campo aberto}

Para analisar as modificações causadas pela música na atividade motora, os animais foram submetidos à tarefa de campo aberto (Chikahisa et al., 2007). O teste do campo aberto consistiu na mensuração das variáveis comportamentais dos indivíduos experimentais, colocados em uma arena limitada por uma parede circular. O interior desta arena, de $280 \mathrm{~cm}$ de diâmetro, teve o assoalho pintado de preto e, divididas em 19 quadrantes. Para testar a atividade exploratória e locomotora, os animais foram colocados no campo aberto para livre exploração por 5min; onde foram anotados os tempos nas seguintes categorias comportamentais: tempo de motilidade (movimentação espontânea entre quadrantes), tempo de imobilidade (ficar imóvel), tempo de exploração (elevar os membros superiores, apoiado nos inferiores) e tempo de auto-limpeza (passar os membros superiores sobre a cabeça).

\section{Análise estatística}

Os resultados foram expressos com média \pm erro padrão da média e submetidos ao teste $t$ de Student, onde foram comparados os grupos de camundongos mantidos 
em ambiente sem música com aqueles submetidos a musica clássica. Um nível de significância menor de $5 \%$ foi utilizado em todas as análises comportamentais realizadas $(\mathrm{p}<0,05)$.

\section{Resultados}

No nado forçado, o teste $t$ de Student mostrou que camundongos submetidos aos estímulos auditivos da música de Mozart em cativeiro, apresentavam uma diminuição na soma cumulativa das durações dos episódios de imobilidade, em relação aos animais controles $(t=3.392 ; \mathrm{p}<0,05)$; com os tempos médios passando de 172,5 $\pm 25,4 \mathrm{~s}$ nos animais controles, para $53,8 \pm 24$ s nos submetidos à música ambiente (Figura 1A). Análise estatística também mostrou uma redução no número de finalizações dos animais submetidos ao ambiente com música $(t=3.392 ; \mathrm{p}<0,05)$; com o número médio de finalizações passando de $14,3 \pm 1,1$ nos animais controles, para 7,5 $\pm 1,7$ nos submetidos à música ambiente (Figura 1B).

No labirinto em cruz elevado, um modelo animal de ansiedade, o teste $t$ de Student não mostrou diferenças estatísticas significativas no tempo de permanência $(t=0,7845 ; \mathrm{p}>0,05)$ e no número de entradas nos braços abertos $(t=0,6547 ; \mathrm{p}>0,05)$ nos camundongos submetidos à música clássica; não caracterizando um efeito ansiolítico. $\mathrm{O}$ tempo de permanência nos braços abertos nos camundongos sob música ambiente foi de $1,25 \pm 0,8$ segundos e no ambiente sem música de 0,5 $\pm 0,2$ segundos (Figura 2A); com número de entradas nos braços abertos de $0,5 \pm 3,0$ para os animais sobre estímulos sonoros e, $0,3 \pm 0,2$ para aqueles onde este estímulo se encontrava ausente (Figura 2B). Entretanto, análise estatística mostrou uma diminuição significativa no tempo de permanência nos braços fechados do labirinto em cruz elevado, nos animais submetidos ao estímulo sonoro $(t=2,547 ; \mathrm{p}<0,05) \mathrm{e}$, um aumento no número de entradas nos braços fechados $(t=3,212$; $\mathrm{p}<0,05)$; bem como no tempo de permanência no quadrante central do labirinto $(t=5,539 ; \mathrm{p}<0,001)$. O tempo de permanência nos braços fechados diminui de $292,8 \pm 3,8 \mathrm{~s}$ para $275,0 \pm 5,8 \mathrm{~s}$ nos animais submetidos à música ambiente (Figura 2A); com o número de entradas nos braços fechados aumentando de $4,0 \pm 1,0$ para 13,5 $\pm 2,7$ (Figura 2B). O aumento de entradas nos braços fechado mostra um aumento na atividade motora; não sendo caracterizado um efeito ansiolítico na diminuição do tempo de permanência nos braços fechados dos animais sob música clássica, pois estes aumentaram o tempo de permanência no quadrante central para 28,6 $\pm 2,1$ s em relação ao tempo de $5,7 \pm 3,6$ s dos animais mantidos no ambiente sem música (Figura 2A).

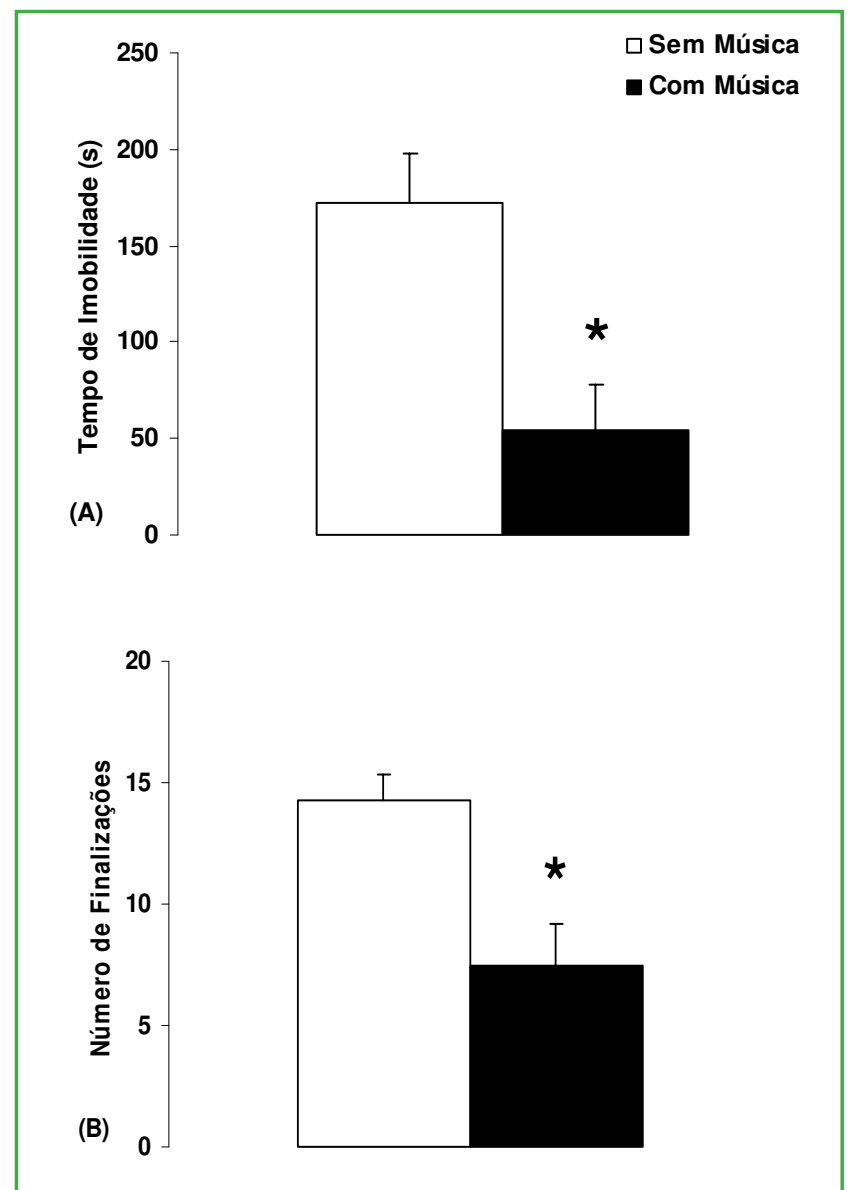

FIGURA 1: Camundongos mantidos sob música de Mozart ambiente durante $24 \mathrm{~h}$ e submetidos ao teste do nado forçado. (A) Tempo de imobilidade. (B) Número de finalizações. Linhas verticais representam \pm o erro padrão da média e as barras a média dos grupos de camundongos ( $\mathrm{n}=8 ;{ }^{*} \mathrm{p}<0,05$; teste $t$ de Student $)$.

No campo aberto, o teste $t$ de Student não mostrou diferenças estatísticas significativas nos tempos de motilidade $(t=0,2707 ; \mathrm{p}>0,05)$, mas mostrou que os camundongos submetidos ao ambiente com música clássica permaneciam menos tempo imóveis $(t=$ 2,278; $<<0,05)$, sugerindo um aumento na atividade 


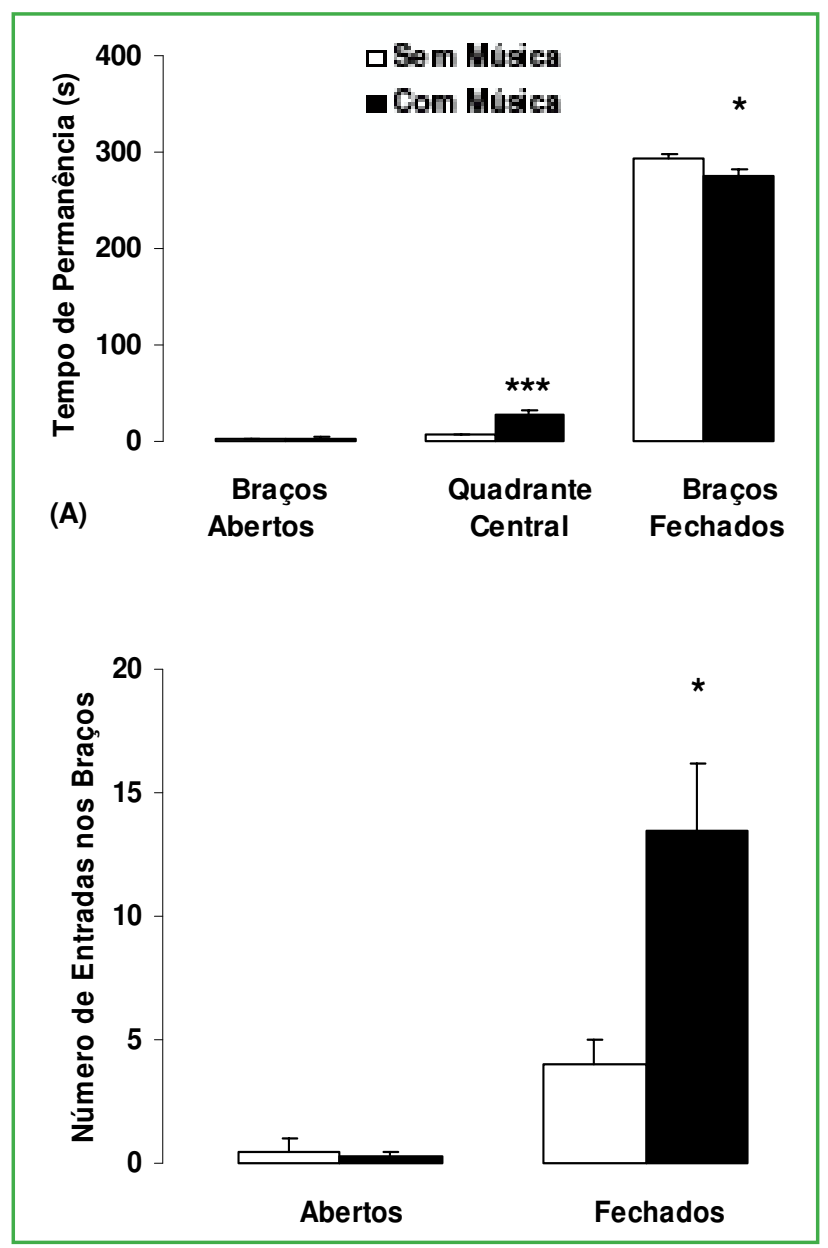

FIGURA 2: Camundongos mantidos sob música de Mozart ambiente durante $24 \mathrm{~h}$ e submetidos ao teste do labirinto em cruz elevado. (A) Tempos de permanência nos braços abertos, quadrante central e braços fechados. (B) Número de entradas nos braços abertos e fechados. Linhas verticais representam \pm 0 erro padrão da média e as barras a média dos grupos de camundongos ( $\mathrm{n}=$ $8 ;{ }^{*} \mathrm{p}<0,05 ;{ }^{* *} \mathrm{p}<0,001 ;$ teste $t$ de Student).

motora. Animais submetidos à música ambiente se movimentaram durante um período de $186,0 \pm 9,9 \mathrm{~s}$ em relação aos 194,3 $\pm 28,7 \mathrm{~s}$ dos animais mantidos em ambiente sem música; enquanto permanecem imóveis por um período de $1,0 \pm 0,5 \mathrm{~s}$ em comparação com os 8,2 $\pm 3,1$ s dos animais mantidos sem música. Os resultados também mostram uma diminuição estatisticamente significativa nos tempos de auto-limpeza $(t=2,449$; $\mathrm{p}<0,05)$ e aumento na atividade exploratória $(t=$ $4,489 ; \mathrm{p}<0,001)$ para os animais submetidos à música ambiente. Os animais colocados num ambiente sem música apresentam um tempo de auto-limpeza de 7,0 $\pm 1,0 \mathrm{~s}$, em relação aos $3,0 \pm 1,2 \mathrm{~s}$ apresentados pelos animais mantidos em ambiente com música. A atividade exploratória dos animais sob estímulo sonoro foi de $117,0 \pm 1,2 \mathrm{~s}$, reduzindo para $63,8 \pm 11,8 \mathrm{~s}$ nos animais não expostos ao ambiente sonoro (Figura 3 ).

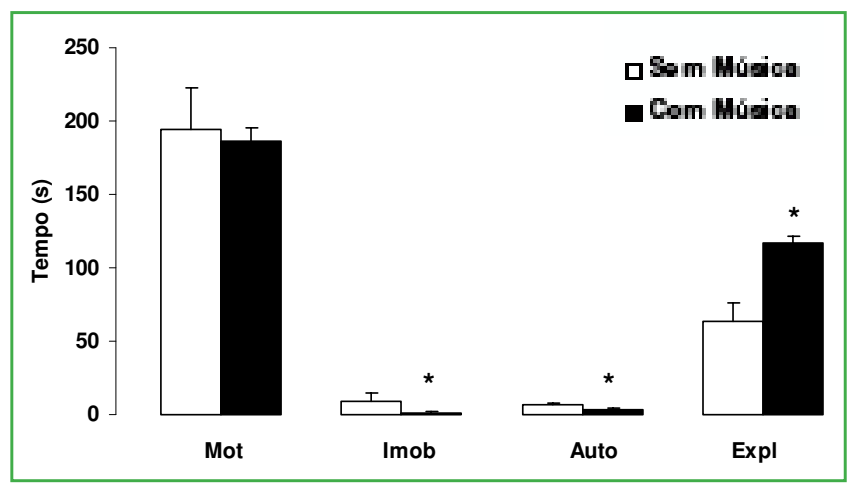

FIGURA 3: Camundongos mantidos sob música de Mozart ambiente durante $24 \mathrm{~h}$ e submetidos ao teste do campo aberto. Estão representados os tempos de motilidade (Mot), de imobilidade (Imob), auto-limpeza (Auto) e atividade exploratória (Expl). Linhas verticais representam \pm 0 erro padrão da média e as barras a média dos grupos de camundongos $\left(\mathrm{n}=8 ;{ }^{*} \mathrm{p}<0,05\right.$; teste $t$ de Student).

\section{Discussão}

A imobilidade no nado forçado é um comportamento de defesa, se instalando após período inicial de emissão intensa de tentativas de evasão da situação estressante e aversiva (Porsolt et al., 1977). No teste do nado forçado, camundongos submetidos à música ambiente apresentaram uma diminuição no tempo de imobilidade e no número de finalizações (Figura 1); mostrando um aumento na representação de um escape dirigido ou na capacidade de enfrentar às condições de impossibilidade de fuga da piscina. A inescapabilidade nestas situações é uma possibilidade e, a emissão de imobilidade, após um período de enfrentamento ativo, como ocorreu com os camundongos submetidos a um ambiente sem música, pode ter a função de conservação de energia para gastos em condições mais favoráveis (Sandrin, 2002) ou ser manifestações de um estado depressivo, que evoluiu filogeneticamente para tornar indiferente o sofrimento da morte em condições adversas extremas (Hoshino, 2006).

A exposição dos camundongos ao labirinto em cruz elevado, não mostrou variação nos níveis de ansiedade entre os dois grupos estudados; com os 
tempos de permanência e entradas nos braços abertos não diferindo estatisticamente (Figura $2 \mathrm{AB}$ ). $\mathrm{O}$ aumento no tempo e número de entradas nos braços abertos ocorre quando estímulos ansiolíticos são capazes de bloquear as respostas inatas de medo/ansiedade para espaços abertos, presentes nestes animais (Pellow et al., 1985). Entretanto, ocorreram diferenças estatisticamente significativa, com diminuição no tempo de permanência e aumento no número de entradas nos braços fechados, nos camundongos submetidos ao ambiente com música clássica (Figura $2 \mathrm{AB}$ ). A redução no tempo de permanência nos braços fechados, deve-se ao aumento do tempo de permanência no quadrante localizado entre os braços abertos e fechados (Figura 2A), causado principalmente pelo aumento no número de entradas nos braços fechados, ou seja, aumento na atividade motora e conflito/avaliação de risco (Figura 2B). A existência da plataforma central no labirinto é a oportunidade de escolha que este aparelho oferece entre as áreas protegidas e desprotegidas. Esta plataforma central tem sido frequentemente associada à tomada de decisão ou conflito de aproximação/esquiva, pois teria a inclusão do tempo gasto na plataforma central e espreita nos braços abertos, que seriam indicativos do conflito associado à situação e a avaliação de risco (Rodgers et al., 1997).

Nossos resultados também mostram não haver uma relação direta entre o grau de ansiedade e tempo de imobilidade ou número de finalizações observadas nos camundongos submetidos ao teste do nado forçado. Tikal (1991) sugeriu que animais que apresentavam tempo de imobilidade mais longo teriam níveis mais altos de ansiedade; hipótese baseada no fato de que muitas drogas antidepressivas, prevista pela redução na imobilidade no teste do nado forçado, são também eficazes no tratamento dos distúrbios de ansiedade. Porém, nossos resultados sugerem que a redução no tempo de imobilidade ou número de finalizações, poderia estar relacionada ao aumento na atividade motora.

A fim de confirmar os efeitos da música clássica sobre a atividade motora geral dos camundongos em cativeiro, utilizamos o teste de campo aberto. Neste teste, o tempo de movimentação espontânea não apresentou diferenças estatísticas, mas foi observada uma redução no tempo de imobilidade nos camundongos submetidos à música clássica, indicando um aumento na atividade motora, reforçando os resultados obtidos no labirinto em cruz elevado. Além disto, animais submetidos à música de Mozart aumentam à atividade exploratória, sugerindo seu efeito no enriquecimento do ambiente para camundongos mantidos em cativeiro. $\mathrm{O}$ aumento na atividade exploratória também pode ser obtido quando o enriquecimento do ambiente é realizado através da roda de corrida, onde o animal realiza exercício voluntário, ou quando estes animais são submetidos à atividade física forçada (Leasure e Jonas, 2008; Cruz et al., 2009).

A redução no tempo de imobilidade no nado forçado e aumento na atividade motora nos testes de campo aberto e labirinto em cruz elevado nos camundongos submetidos a um ambiente com música clássica, sugerem um compartilhamento de mecanismos neurais comuns, ao menos parciais, decorrentes da ativação de mecanismos responsáveis pelos processos neurofisiológicos básicos e pelo aumento da atividade motora. Ao lado de outras espécies, comparações destes resultados são difíceis devido aos vários estímulos acústicos empregados em outras instituições; mas mostram um efeito enriquecedor da música clássica, como foi estabelecido para várias espécies de animais mantidos em cativeiro (Wells et al., 2002; 2006; 2008; Videan et al., 2007; Wells, 2009). Entretanto, levam a um questionamento da validade da imobilidade do nado forçado como manifestação similar ou relacionada à depressão psiquiátrica, ao menos na forma em que ela é abordada na atualidade.

Além disto, devemos considerar que a música apresenta flutuações nos níveis de som, frequência e tempo, capazes de induzir mudanças fisiológicas e comportamentais em roedores. Atualmente, podemos estabelecer que as respostas dos camundongos à música dependam do sistema auditivo ou oscilações do ar. Se a resposta é mediada pelo sistema auditivo, os sons entre 0,5 a $120 \mathrm{kHz}$, presentes na música clássica de Mozart, estariam envolvidos nos efeitos comportamentais observados neste estudo, pois os camundongos podem ouvir apenas nesta faixa de frequência (Ehret, 1975). Existe também a possibilidade que o efeito da música não seja mediado pelo sistema auditivo, mas por oscilações do ar criadas pelo som (Chikahisa et al., 2007). Estímulos ambientais, incluindo os somatossensoriais, podem estar 
relacionados com os níveis de ansiedade em roedores. Por exemplo, animais manipulados durante o período pós-natal apresentam menor grau de ansiedade que os controles, em testes comportamentais (Chapillon et al., 2002).

Outros estudos são necessários para determinar os efeitos à longo prazo destes estímulos sonoros e desvendar os elementos acústicos específicos que estes animais respondem, determinando seu efeito enriquecedor e capacidade de induzir alterações neurofisiológicas.

\section{Referências}

Chapillon, P.; Patin, V.; Roy, A.; Vincent, A.; Caston, J. 2002. Effects of pre- and postnatal stimulation on developmental, emotional, and cognitive aspects in rodents: a review. Developmental Psychobiology, 41 (4): 373-387.

Chikahisa, S.; Sano, A.; Kitaoka, K.; Miyamoto, K. I.; Sei, H. 2007. Anxiolytic effect of music depends on ovarian steroid in female mice. Behavioural Brain Research, 179 (1): 50-59.

Cruz, J. G. P.; Dal Magro, D. D.; Cruz, J. N.; Roecker, R. 2009. Efeitos da administração aguda de etanol sobre a aprendizagem no reconhecimento de objetos em camundongos nadadores. Revista Eletrônica de Farmácia, 6 (2): 123-138.

Ehret, G. 1975. Masked auditory thresholds, critical ratios, and scales of the basilar membrane of the housemouse (Mus musculus). Journal of Comparative Physiology, 103 (1): 329-341.

Hoshino, K. 2006. A perspective biológica do luto. In: Guilhardi, H. J. G. \& Aguirre, N. C. (Eds.). Sobre comportamento e cognição. ESETEC Editores Associados, Santo André, Brasil, p.313-326.

Leasure, J. L.; Jones, M. 2008. Forced and voluntary exercise differentially affects brain and behavior. Neuroscience, 156 (3): 456-465.

McCarthy, D. O.; Ouimet, M. E.; Daun, J. M. 1992. The effects of noise stress on leukocyte function in rats. Research in Nursing \& Health, 15 (2): 131-137.

McCraty, R.; Barrios-Choplin, B.; Atkinson, M.; Tomasino, D. 1998. The effects of different types of music on mood, tension and mental clarity. Alternative Therapies in Health and Medicine, 4 (1): 75-84.

Michelan, C. M.; Michelan, L. D.; Paula, H. M. G.; Hoshino, K. 2006. Imobilidade tônica e imobilidade do nado forçado em cobaias. Revista de Etologia, 8 (2): 89-95.

Morton, A. J.; Hickey, M. A.; Dean, L. C. 2001. Methamphetamine toxicity in mice is potentiated by exposure to loud music. Neuroreport, 12 (15): 3277-3281.

Nakamura, T.; Tanida, M.; Niijima, A.; Hibino, H.; Shen, J.; Nagai, K. 2007. Auditory stimulation affects renal sympathetic nerve activity and blood pressure in rats. Neuroscience Letters, 416 (2): 107-112.
National Research Council. 1996. Guide for the care and use of laboratory animals. $7^{\text {th }}$ ed. National Academy Press, Washington DC, USA, 139pp.

Newberry, R. C. 1995. Environmental enrichment: increasing the biological relevance of captive environments. Applied Animal Behavioural Science, 44 (2-4): 229-243.

Núñez, M. J.; Mañá, P.; Liñares, D.; Riveiro, M. P.; Balboa, J.; Suárez-Quintanilla, J.; Maracchi, M.; Ménez, M. R.; Lóopez, J. M.; Freire-Garabal, M. 2002. Music, immunity, and cancer. Life Sciences, 71 (9): 1047-1057.

Pellow, S.; Chopin, P.; File, S. E.; Briley, M. 1985. Validation of open: closed arm entries in the elevated plus-maze as a measure of anxiety in the rat. Pharmacology Biochemistry and Behavior, 24 (3): 525-529.

Porsolt, R. D.; Le Pichon, M.; Jalfre, M. 1977. Depression: a new animal model sensitive to antidepressant treatments. Nature, 266 (5604): 730-732.

Rodgers, R. J.; Cao, G. J.; Dalvi, A.; Holmes, A. 1997. Animal models of anxiety: an ethological perspective. Brazilian Journal of Medical and Biological Research, 30 (3): 289-304.

Sandrin, M. F. N. 2002. Densidade populacional e padrões comportamentais do hamster sírio Mesocricetus auratus (Waterhouse, 1839) (Rodentia: Muridae) no nado forçado. Tese de doutorado, Universidade Estadual Paulista de Botucatu, Brasil, $197 \mathrm{pp}$.

Sherwin, C. M. 2002. Comfortable quarters for mice in research institutions. In: Reinhardt, V. \& Reinhardt, A. (Eds). Comfortable quarters for laboratory animals. $9^{\text {th }}$ ed. Animal Welfare Institute, Washington, USA, p.6-17.

Sutoo, D.; Akiyama, K. 2004. Music improves neurotransmission: demonstration based on the effect of music on blood pressure regulation. Brain Research, 1016 (2): 255-262.

Tikal, K. 1991. Tonic immobility and factors influencing its duration in rats. Homeostasis in Health and Diseases, 33 (4): 199-203.

Videan, E. N.; Fritz, J.; Howell, S.; Murphy, J. 2007. Effects of two types and genre of music on social behaviour in captive chimpanzees (Pan troglodytes). Journal of American Association Laboratory Animal Science, 46 (1): 66-70.

Wells, D. L. 2009. Sensory stimulation as environmental enrichment for captive animals: a review. Applied Animal Behaviour Science, 118 (1-2): 1-11.

Wells, D. L.; Coleman, D.; Challis, M. G. 2006. A note on the effect of auditory stimulation on the behaviour and welfare of zoo-housed gorillas. Applied Animal Behavioural Science, 100 (3-4): $327-$ 332.

Wells, D. L.; Graham, L.; Hepper, P. G. 2002. The influence of auditory stimulation on the behaviour of dogs housed in a rescue shelter. Animal Welfare, 11 (4): 385-393.

Wells, D. L.; McDonald, C. L.; Ringland, J. E. 2008. Color preferences in gorillas (Gorilla gorilla gorilla) and chimpanzees (Pan troglodytes). Journal of Comparative Psychology, 122 (2): 213-219.

Yalch, R. F.; Spangenberg, E. R. 2000. The effects of music in a retail setting on real and perceived shopping times. Journal of Business Research, 49 (2): 139-147. 